\title{
Computed tomography grading schemes used to predict cerebral vasospasm after aneurysmal subarachnoid hemorrhage: a historical review
}

\author{
Paul Klimo JR., M.D., M.P.H., AND Richard H. Schmidt, M.D., Ph.D. \\ Department of Neurosurgery, Children's Hospital Boston, Massachusetts; and Department of \\ Neurosurgery, University of Utah, Salt Lake City, Utah
}

\begin{abstract}
$\checkmark$ The elucidation of predictive factors of cerebral vasospasm following aneurysmal subarachnoid hemorrhage (SAH) is a major area of both clinical and basic science research. It is becoming clear that many factors contribute to this phenomenon. The most consistent predictor of vasospasm has been the amount of SAH seen on the postictal computed tomography scan. Over the last 30 years, it has become clear that the greater the amount of blood within the basal cisterns, the greater the risk of vasospasm. To evaluate this risk, various grading schemes have been proposed, from simple to elaborate, the most widely known being the Fisher scale. Most recently, volumetric quantification and clearance models have provided the most detailed analysis. Intraventricular hemorrhage, although not supported as strongly as cisternal $\mathrm{SAH}$, has also been shown to be a risk factor for vasospasm.
\end{abstract}

\section{KEY WORDS • computed tomography • vasospasm • subarachnoid hemorrhage • predictive value}

$\mathrm{B}$ LOOD released under high pressure into the basal subarachnoid cisterns as a result of a ruptured aneurysm can trigger a cascade of molecular events that leads to a narrowing of the major intracranial arteries, which is called cerebral vasospasm. Radiographically apparent vasospasm will develop in approximately 60 to $70 \%$ of all patients with aneurysmal SAH. Of these, two thirds will suffer ischemia severe enough to cause transient or permanent neurological deficits, so-called symptomatic or clinical vasospasm, or DINDs. ${ }^{31}$ Extreme vasospasm can ultimately lead to infarction. ${ }^{59}$ Vasospasm follows a typical time course in that its onset usually occurs within 1 week after the hemorrhage, it reaches its maximum severity between Days 7 and 10 post-SAH, and it usually dissipates after 14 to 21 days.

Although the impact of vasospasm on the outcome of SAH has steadily declined because of medical and surgical advances, both the disease and its treatment continue to be major sources of morbidity and mortality. Based on data from the International Cooperative Study on the Timing of Aneurysm Surgery, which was conducted in the early 1980s, researchers showed that clinical vasospasm permanently affected $13.5 \%$ of all patients and accounted for $33 \%$ of deaths and disabilities. ${ }^{32}$ More recent studies indicate that 5 to $11 \%$ of patients continue to suffer permanent disability as a result of vasospasm. ${ }^{13,61,64,65}$

Abbreviations used in this paper: $\mathrm{CSF}=$ cerebrospinal fluid; $\mathrm{CT}=$ computed tomography; DINDs = delayed ischemic neurological deficits; $\mathrm{HN}=$ Hounsfield number; $\mathrm{ICH}=$ intracerebral hemorrhage; IVH = intraventricular hemorrhage; NPV = negative predictive value; $\mathrm{PPV}=$ positive predictive value; $\mathrm{SAH}=$ subarachnoid hemorrhage; $\mathrm{TCD}=$ transcranial Doppler.

\section{Predictive Models for Vasospasm}

Much work has been done to elucidate factors that are predictive of cerebral vasospasm. The ability to predict vasospasm would be a powerful tool for the neurointensivist. Ideally, factors found to be associated with vasospasm could collectively constitute a model of prediction that would carry a sufficient positive and negative predictive capability to make it clinically useful. For those patients deemed to be at high risk, therapies could be instituted earlier and more aggressively; those who are thought to be at low risk could avoid the significant potential complications and costs associated with vasospasm treatment. ${ }^{67}$ The most useful predictors are those that can be easily and consistently measured and obtained shortly after the patient presents for treatment and that stratify the outcome of interest (that is, vasospasm) to the greatest degree. In essence, application of these predictors would enable the clinician to provide cost-effective, evidence-based patient care.

Variables predictive of vasospasm can be categorized as modifiable or nonmodifiable. The nonmodifiable variables that have been investigated include patient age, ${ }^{8,43,58}$ race, ${ }^{51}$ site of the aneurysm, ${ }^{57}$ preexisting hypertension, ${ }^{46}$ cocaine or cigarette use,,$^{10,44,72}$ neurological grade, $, 846,57,58$ genetically predetermined composition of certain proteins, ${ }^{4,36}$ and the amount of hemorrhage on CT scans. Potentially modifiable factors include treatment type, ${ }^{12,29,56,59}$ velocity of blood flow measured with TCD ultrasonography, ${ }^{21,47,53}$ serum markers (leukocytosis, ${ }^{49}$ hyperglycemia, ${ }^{8,42}$ thrombocytopenia, ${ }^{26}$ antiphospholipid antibodies, ${ }^{28}$ complements, ${ }^{35}$ and others ${ }^{48,69}$ ), and CSF markers (for example, lipid peroxides $^{30}$ ).

Among the factors that might be included in a model of 
P. Klimo Jr. and R. H. Schmidt

TABLE 1

Literature review of the efficacy of the various SAH grading scales based on CT scans

\begin{tabular}{|c|c|c|c|c|c|c|}
\hline Authors \& Year & No. of Patients & Dichotomous Variable & $\%$ Sensitivity & $\%$ Specificity & $\% \mathrm{PPV}$ & $\% \mathrm{NPV}$ \\
\hline Fisher, et al., 1980 & 47 & Grade III SAH & 92 & 95 & 96 & 91 \\
\hline Mizukami, et al., 1980 & 34 & $\begin{array}{l}\text { high density } \\
\text { w/in Days } 1 \text { to } 4\end{array}$ & 100 & 67 & 85 & 100 \\
\hline Mohsen, et al., 1984 & 92 & Hyperdense Grade III & 71 & 64 & 63 & 73 \\
\hline Knuckey, et al., 1985 & 46 & diffuse SAH & 47 & 87 & 64 & 77 \\
\hline Friedman, et al., 2002 & 40 & $20 \mathrm{ml}$ of blood & 46 & 100 & 100 & 44 \\
\hline
\end{tabular}

prediction, the characteristics of SAH on the initial CT scan obtained shortly after the ictal event have been shown consistently to be one of the most, if not the most, powerful predictors of cerebral vasospasm. ${ }^{23}$ We review the literature on the use of CT scanning to assess aneurysmal SAH and consider how grading schemes have evolved over the last 30 years, from initial descriptions in the late 1970s to the volumetric and clearance models of today. We also compare the different scales by calculating their specificity, sensitivity, and the PPV and NPV, when applicable.

\section{The 1970s and 1980s}

The relationship between cerebral vasospasm and a high density of blood in the basal subarachnoid cisterns on the initial CT scan was first described by Takemae, et al. ${ }^{70}$ in 1978. This was followed by a more in-depth analysis 2 years later in the English literature, ${ }^{50}$ in which CT scans were obtained in 177 patients within 3 weeks of their SAH (scans were obtained in 111 patients within the first 4 days). The presence of a high density of blood observed in the basal cisterns (basal frontal interhemispheric fissure, sylvian stem, and sylvian cistern), frontal interhemispheric fissure, insular cistern, parenchyma, and ventricles was recorded. Rates for cerebral vasospasm, as confirmed by angiography, were as follows if a high-density clot was detected on CT scans post-SAH: $84.6 \%$ of cases on scans made within the first 4 days, $75 \%$ of cases on Days 5 to 7 , and $86.7 \%$ after Day 7 . In eight cases in which no high density was detected within 4 days of the hemorrhage, no vasospasm occurred. Thus, the presence of high density of blood on CT scans obtained within 4 days had excellent sensitivity and NPV, but the study population still contained false-positive cases (Table 1). Other authors subsequently supported this association between high density of blood and vasospasm. ${ }^{3,54}$ Although the authors of these early papers analyzed the presence of SAH within certain intracranial compartments, they did not attempt to quantify the amount of hemorrhage.

One of the first attempts to provide a more detailed description of the degree of SAH was made by Davis, et al., ${ }^{11}$ in 1980. In their study, CT scans obtained in 50 patients within 4 days of the hemorrhage were classified according to a four-point scale (Table 2). The authors found that of the 22 patients in whom severe vasospasm developed, 14 (64\%) had a Grade 3 or 4 scan, and of the 24 patients with no or mild spasm, $19(79 \%)$ had a Grade 1 or 2 scan. The primary limitation of this classification was that it did not allow distinctions to be made between large and small collections of blood in a specific subarachnoid compartment.
With few exceptions, ${ }^{22}$ authors in the 1980s continued to support the theory that there is a positive correlation between the amount of cisternal SAH and the development of vasospasm. Mohsen, et al., ${ }^{52}$ created three categories to describe hyperdensity consistent with hemorrhage detected on the CT scan (Table 3). They found that of those with the thickest amount of hemorrhage, so-called Hyperdense Grade III, in $62.5 \%$ delayed cerebral ischemia developed, and $39.6 \%$ had a poor outcome. No patient in the group with Hyperdense Grade I hemorrhages experienced ischemia and 33\% of those in Group II did. Nevertheless, the presence of a Hyperdense Grade III hemorrhage on CT scans has poor positive and negative predictive capabilities (Table 1). Pickard, et al., 55 also used the $2-\mathrm{mm}$ cutoff in grading their scans for their multicenter randomized trial of oral nimodipine. Knuckey and colleagues ${ }^{39}$ divided the admission CT scans of 46 consecutive patients into the following four categories: 1, no subarachnoid blood; 2 , blood localized to one cistern; 3 , blood localized to two unilateral cisterns; and 4, diffuse subarachnoid blood. Clinical vasospasm developed in $0,37,20$, and $64 \%$ of patients in these four categories, respectively. When the authors collapsed the four categories into two (Group I comprised patients from the first three categories and Group II were those with diffuse subarachnoid blood), they found that this dichotomization resulted in a good specificity of $87 \%$, but a sensitivity of $47 \%$ (Table 1 ).

Arguably, the most well-known analysis of the relationship between the location and amount of subarachnoid blood and the development of vasospasm was performed by Fisher, et al. ${ }^{15}$ In 1980, these authors published a retrospective study in which they found a high correlation (23 of 24 patients) between severe radiographically (graded according to the scale in Fisher, et al. ${ }^{16}$ ) and clinically confirmed vasospasm and the presence of subarachnoid clots greater than $5 \times 3 \mathrm{~mm}$ in diameter in cisterns and fissures

TABLE 2

Aneurysmal SAH grading scale*

\begin{tabular}{cc}
\hline \hline Grade & Description \\
\hline 1 & no subarachnoid blood \\
minimal subarachnoid blood (sylvian fissure[s] \\
\&/or interhemispheric fissure) \\
3 & moderate subarachnoid blood (sylvian fissure [s], \\
\&/or interhemispheric fissure, \& suprasellar cistern) \\
extensive subarachnoid blood (sylvian fissure[s], \\
interhemispheric fissure, suprasellar cistern, \& \\
ambient cistern)
\end{tabular}

* Modified from Davis, et al. 


\section{Predicting vasospasm by using computed tomography scanning}

TABLE 3

Hyperdense SAH grading scale*

\begin{tabular}{|c|c|}
\hline Grade & Description \\
\hline I & $\begin{array}{l}\text { localized thin layer of blood }(<2 \mathrm{~mm}) \text { in basal cisterns } \\
\text { on one side or in one sylvian fissure only, w/o diffuse } \\
\text { deposition of blood in the subarachnoid space }\end{array}$ \\
\hline II & $\begin{array}{l}\text { localized thick layer of blood }(\geq 2 \mathrm{~mm}) \text { in the basal } \\
\text { cisterns, sylvian fissure, or interhemispheric fissure, } \\
\text { w/o diffuse deposition in the subarachnoid space, or } \\
\text { diffuse deposition w/o a thick layer }\end{array}$ \\
\hline III & $\begin{array}{l}\text { diffuse deposition of blood in the subarachnoid } \\
\text { space } \& \text { basal cisterns, \& basal cisterns filled w/ a } \\
\text { thick layer of blood }(\geq 2 \mathrm{~mm} \text { ) on at least one side }\end{array}$ \\
\hline
\end{tabular}

* Modified from Mohsen, et al.

in the horizontal plane, or clots greater than $1 \mathrm{~mm}$ thick in the vertical plane. ${ }^{18}$ No clinical vasospasm occurred in the 23 patients in whom either no or diffuse SAH was present. Based on their study population, the presence of a Grade III SAH was associated with a PPV of $96 \%$ and an NPV of $91 \%$. The authors followed this report with a prospective study involving 41 cases that confirmed their earlier results. ${ }^{37}$ In this study, 20 of 22 patients with thick SAH suffered severe vasospasm, whereas 14 of 19 patients with no or diffuse blood, or blood outside the subarachnoid space, did not. The authors discussed each of the false positives (two) and false negatives (five) and argued that they could all be explained by limitations of the CT scans as the basis for estimating the extent and location of blood. The Fisher-Kistler grading scale quickly became and continues to be the most commonly used instrument for classification of admission head CT scans in patients with aneurysmal SAH (Table 4; see also Fraser, et al. ${ }^{17}$ ). The main advantage of the Fisher-Kistler scale is its ease of use and apparently high predictive capability.

Nevertheless, this scale has come under criticism recently. Some authors have suggested that it cannot be used to distinguish easily between a Grade 2 and 3 hemorrhage. ${ }^{2,45}$ Kistler, et al. ${ }^{37}$ commented on this so-called gray area, which they thought occurred most often when blood was present around the suprasellar, sylvian, or basal frontal interhemispheric frontal cisterns. Fujita ${ }^{19}$ further argued that the Fisher classification was subjective and

TABLE 4

Fisher SAH scale*

\begin{tabular}{ll}
\hline \hline Grade & \multicolumn{1}{c}{ Description } \\
\hline 1 & no blood \\
2 & diffuse deposition or thin layer, no clots $>3 \mathrm{~mm}$, \\
& thick or vertical layers $>1 \mathrm{~mm}$ thick \\
3 & dense collection of blood $>1 \mathrm{~mm}$ thick in the \\
vertical plane (interhemispheric fissure, insular \\
cistern, or ambient cistern), or $>5 \times 3 \mathrm{~mm}$ in \\
longitudinal \& transverse dimension \\
in the horizontal plane (stem of sylvian fissure, \\
& sylvian cistern, \& interpeduncular cistern) \\
& intracerebral or intraventricular clots, but w/ only \\
& diffuse or no blood in basal cisterns \\
\hline
\end{tabular}

* Modified from Kistler, et al. lacked quantitativeness. For example, in the randomized trial investigating nimodipine reported by Allen, et al., ${ }^{2}$ the review committee had difficulty in applying the Fisher scale and concluded that this scale could not be reproduced and applied accurately to their scans. More recently, Smith, et al., ${ }^{66}$ found that the Fisher grade poorly predicted clinical vasospasm in modern practice, where use of hypervolemic, hypertensive therapy and nimodipine has become standard.

We believe that the Fisher scale is incomplete in its description because it does not allow classification of patients with a Grade $3 \mathrm{SAH}$ in the basal cisterns in addition to significant IVH or intraparenchymal hemorrhage, a scenario that is commonly seen in clinical practice. Because we thought that the presence of blood in the parenchyma-or, more importantly, in the ventricle-was an additional risk factor for the development of vasospasm, we created a simple modification of the Fisher scale by adding a " $3+$ 4 " category for patients with combined dense cisternal hemorrhage and an intraventricular or intraparenchymal clot greater than $5 \mathrm{ml} .^{38} \mathrm{In}$ our study of lumbar CSF drainage, these patients had the highest risk of suffering symptomatic vasospasm. Without lumbar CSF drainage, symptomatic vasospasm rates in our modified grading scheme were $0 \%$ in patients whose condition was classified Grade 1,3.6\% in Grade 2, 40\% in Grade 3, and 68\% in Grade $3+4$; with lumbar CSF drainage, vasospasm rates fell to $13 \%$ in Grade 3 and $35 \%$ in Grade $3+4$.

Several groups proposed an alternative means to quantify the extent of SAH by calculating the $\mathrm{HN}$ in various intracranial compartments. ${ }^{19,62,68}$ Fujita $^{19}$ believed that the "strength of the local high density of the cerebral cistern would express the concentration of blood clot" and should serve as the basis for stratifying patients. In his case-controlled study of 36 patients, the $\mathrm{HN}$ of the high-density area was based on the mean value of 12 pixels. Multiple $\mathrm{HN}$ values in the basal cisterns were obtained and averaged. The pre- and postoperative averaged HN values in the patients with vasospasm were significantly higher than in those without it. The HN values in the patients without vasospasm were always 73 or less, whereas those in patients with vasospasm were always 68 or more. Based on this, a scale of increasing density from I to $\mathrm{V}$ was developed. Ultra-early surgery to remove blood from the cisterns as extensively as possible, concurrent with the treatment of the ruptured aneurysm, was recommended for any patient with a mean HN score of 68 or more (corresponding to Scores III-V on the density scale).

Because most investigators focused their attention on the qualitative and quantitative analysis of blood within the basal subarachnoid spaces, reports in which blood in other compartments was evaluated were slow to emerge. Davis and colleagues ${ }^{11}$ found no relation between the presence of intraventricular and/or intraparenchymal hematomas and the presence of vasospasm in their 1980 paper. Using data collected from the International Cooperative Study on the Timing of Aneurysm Surgery, Adams, et al., ${ }^{1}$ found a strong correlation between the amount of cisternal $\mathrm{SAH}$, as graded using the Fisher scale, and vasospasm, but failed to demonstrate a similar correlation with IVH or ICH.

In 1988, Hijdra and colleague ${ }^{24,25}$ were the first to demonstrate the importance of intraventricular blood. These authors used data acquired from a randomized controlled 
TABLE 5

Scale used for grading of SAH and IVH*

\begin{tabular}{cl}
\hline \hline Compartment & \multicolumn{1}{c}{ Description } \\
\hline subarachnoid $\dagger$ & no blood \\
0 & small amount of blood \\
1 & moderate amount of blood \\
2 & completely filled w/ blood \\
3 & \\
intraventricular $\$$ & no blood \\
0 & sedimentation of blood in posterior part \\
1 & partly filled w/ blood \\
2 & completely filled w/ blood \\
3 &
\end{tabular}

* Modified from Hijdra and colleagues (see refs. 24 and 25).

$\dagger$ Ten cisterns are analyzed: frontal interhemispheric (one); lateral sylvian fissure, medial sylvian fissure, suprasellar, and ambient (two each); and quadrigeminal (one). Therefore, the total amount of subarachnoid blood ranges from 0 to 30 points on the scale.

\$ The four ventricles are analyzed. Therefore, the total amount of blood within the four ventricles ranges from 0 to 12 points on the scale.

trial conducted to test the effect of the antifibrinolytic agent tranexamic acid in patients with SAH to study $176 \mathrm{pa}-$ tients prospectively for the development of numerous outcomes, including delayed cerebral ischemia. The amount of subarachnoid and intraventricular blood seen on CT scans was scored semiquantitatively as the sum of scores ranging from 0 to 3 for each of 10 cisterns (Table 5). An example of the grading scheme is shown in Fig. 1.

Hijdra and colleagues ${ }^{24,25}$ reported that delayed cerebral ischemia occurred in 57 patients (32\%). Using a stepwise logistic regression model, the authors found that the most significant risk factor for the development of delayed cerebral ischemia was the amount of subarachnoid blood present on CT scans within 72 hours after aneurysm rupture; the next most important entry variable was the amount of intraventricular blood. The authors hypothesized that IVH could contribute to the risk that delayed cerebral ischemia could develop by causing ventricular dilation, which may further impair blood flow in patients with marginal vascular reserve as a result of vasospasm. Other potential causes cited by the authors were hyponatremia and a decrease in intravascular blood volume. Contrary to reports published earlier, ${ }^{15,54}$ the authors did not find a relationship between the location of the subarachnoid blood on admission and the site of the delayed cerebral ischemic lesion. Although their scale was theoretically appealing and has been used by other authors, some have criticized it, claiming that it has limited interobserver reliability and is cumbersome to use in everyday clinical practice. ${ }^{71}$

\section{The 1990s and the New Millennium}

Although researchers repeatedly demonstrated that the risk of symptomatic vasospasm is directly related to the quantity of initial cisternal SAH, ${ }^{21}$ controversy over whether the presence of IVH predisposes a patient to vasospasm continued because some researchers found a correlation ${ }^{9,25,46}$ and others did not. ${ }^{1,6,18,21}$ In 1993, Brouwers, et al., ${ }^{6}$ using the Hijdra grading scheme for SAH and IVH, found that a sum score of cisternal blood above the median value was significantly related to ischemia, infarction, and poor outcome. The presence of intraventricular blood or an intracerebral hematoma was related to poor outcome
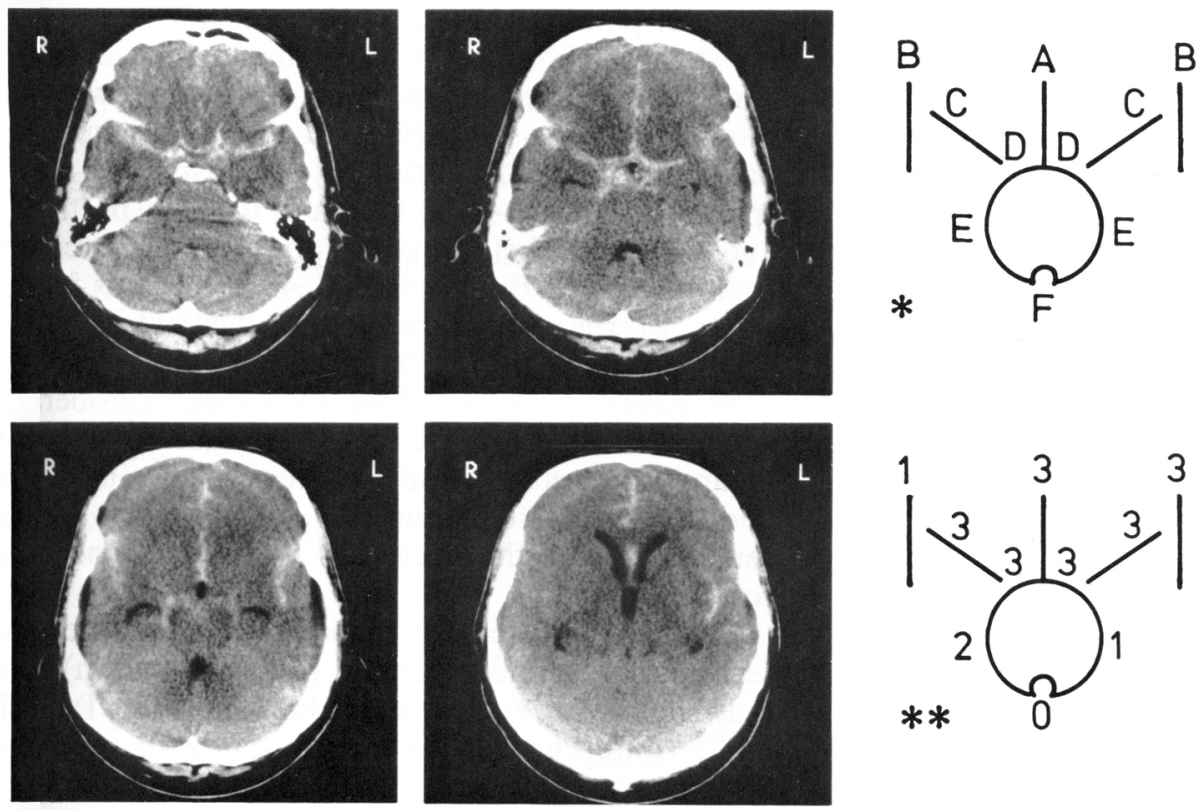

FIG. 1. An example of the grading scheme used by Hijdra, et al. Upper: Axial CT scans and diagram identifying the 10 basal cisterns: frontal interhemispheric (A), lateral sylvian fissure (B), medial sylvian fissure (C), suprasellar (D), ambient (E), and quadrigeminal (F). Lower: Axial CT scans and diagram indicating the amount of blood in each cistern as graded from 0 to 3 (see Table 5 for explanation of numbers used in the grading system). Reprinted with permission from Hijdra A, Brouwers PJ, Vermeulen M: Grading the amount of blood on computed tomograms after subarachnoid hemorrhage. Stroke 21:1156-1161, 1990. 


\section{Predicting vasospasm by using computed tomography scanning}

TABLE 6

Scale used for grading of SAH on CT scans*

\begin{tabular}{ll}
\hline \hline Grade & \multicolumn{1}{c}{ Criteria $\dagger$} \\
\hline 0 & no SAH or IVH \\
1 & minimal/thin SAH, no IVH in both lat ventricles \\
2 & minimal/thin SAH, w/ IVH in both lat ventricles \\
3 & thick SAH, no IVH in both lat ventricles \\
4 & thick SAH, w/ IVH in both lat ventricles \\
\hline
\end{tabular}

* Modified from Claasen, et al.

$\dagger$ Thick SAH is defined as completely filling one or more cistern(s) or fissure(s).

but not to infarction (clinically apparent vasospasm was not specifically measured). Qureshi, et al., ${ }^{57}$ also found that the presence of intraventricular blood was not independently associated with symptomatic vasospasm in a multivariate analysis.

Claassen, et al., ${ }^{9}$ used the method described by Hijdra, et al., ${ }^{25}$ to study 276 consecutively admitted patients. They also calculated the volume of an intraparenchymal hemorrhage by using the $\mathrm{ABC} / 2$ method. ${ }^{41}$ Based on a multivariate logistic regression model in which CT scans and clinical variables were used, the authors found four independent predictors of delayed cerebral ischemia: mean arterial pressure greater than $112 \mathrm{~mm} \mathrm{Hg}$, IVH in both lateral ventricles, mean blood flow velocities greater than $140 \mathrm{~cm} / \mathrm{sec}$ on TCD ultrasonography studies obtained within 5 days of $\mathrm{SAH}$, and thick SAH in any cistern or fissure. Of these predictors, IVH was the strongest and was associated with a threefold increase in the risk of delayed cerebral ischemia. Similar results were obtained in a repeated analysis in which infarction attributable to vasospasm was used as the dependent variable. Although intraparenchymal hemorrhage was predictive of infarction in the study, this relationship was not significant when both $\mathrm{CT}$ and clinical variables were considered. The authors constructed a new $\mathrm{CT}$ rating scale for SAH by combining variables that were equivalently predictive of both delayed cerebral ischemia and infarction in the combined CT logistic models, and that were reasonable to apply to a clinical scale (Table 6). This new CT scale was compared with the Fisher scale for differentiation between different levels of risk for delayed cerebral ischemia and infarction, and was found to be superior.

Using the largest known database of more than 3000 patients with aneurysmal SAH who participated in one of four prospective randomized trials of tirilazad, Macdonald, et al. ${ }^{46}$ elucidated factors associated with vasospasm. The SAH on the admission CT scan was classified, based on the maximal amount of blood, as none, diffuse thin or thick, or localized thin or thick, and IVH and ICH were recorded as present or absent. Of the 3567 patients, thick $\mathrm{SAH}$ was observed on the admission CT scan in $66 \%$, IVH was present in $45 \%$, ICH was present in $23 \%$, and vasospasm developed in $30 \%$. For all patients, significant predictors of vasospasm were as follows: age (peak incidence among patients 40-59 years old); history of hypertension; neurological grade; cisternal blood clot thickness; aneurysm size; presence of IVH; and prophylactically induced hypertension, but not presence of ICH.
We do not believe that IVH contributes to the risk that vasospasm may develop because of ventricular dilation as set forth by Hijdra, et al. ${ }^{25}$ because all of the patients in our study who had significant IVH underwent placement of an external ventricular drain. ${ }^{38}$ We believe the increased risk is due to a higher load of spasmogens in the CSF and to stagnation of CSF (attributable to the use of an external ventricular drain, which impedes the natural intracranial circulation of CSF). The patients in the $3+4$ group that we have described predominantly had IVH with SAH, and cases of pure ICH with SAH were rare. We thus believe that the excess risk in the $3+4$ Group is due to IVH. Patients with pure ICH or IVH with scant SAH had a low risk of vasospasm.

Despite overwhelming evidence, investigators continued to debate the importance of SAH seen on the initial CT scan. In a case-controlled design, Schaller, et al., ${ }^{63}$ evaluated the risk of vasospasm developing, as detected on TCD ultrasonography studies, in relation to the amount of subarachnoid blood observed. They chose a scale that had been used by others, ${ }^{20}$ in which Grade I is characterized by a thin and localized layer of subarachnoid blood; Grade II has thick layer in two of three subarachnoid compartments or in one subarachnoid compartment and the cortical surface; and Grade III is a severe diffuse SAH involving all subarachnoid compartments, or two of three plus the cortical surface. Schaller, et al., found no correlation between the grade of the subarachnoid blood and the degree of vasospasm, and incorrectly concluded that "the initial CT scan should no longer be used as the indicator for occurrence and severity of the multifactorial entity vasospasm." They did not differentiate between radiographically and clinically apparent vasospasm, and their definition of "severe vasospasm" as a mean blood flow velocity of greater than $160 \mathrm{~cm} / \mathrm{second}$ on TCD ultrasonography studies had poor specificity. A similar investigation was performed by Grosset, et al..21 in which, contrary to the previous study, the authors did find that the proportion of patients in whom DINDs developed was higher with increasing amounts of subarachnoid blood.

More accurate quantification of cisternal SAH required the development of new computer software. These computer-based techniques have the potential advantage of objective and precise quantification of cisternal hemorrhage volume. In 1994, Broderick and colleagues ${ }^{5}$ analyzed digitized CT scans to measure the volume of subarachnoid blood in patients with aneurysmal SAH. The mean volume of SAH was $21 \mathrm{ml}$, and the authors found that SAH volume served as a powerful predictor of mortality rates. These authors, however, did not study the relationship of SAH to vasospasm. In 2002, Friedman, et al., ${ }^{18}$ analyzed the CT scans of 40 patients within 72 hours of the ictus by using a quantification technique developed at their institution. Hemorrhage volumes were quantified for the interhemispheric, left and right suprasellar cisterns, left and right ambient cisterns, left and right basal sylvian fissures, left and right lateral sylvian fissures (insular cistern), quadrigeminal cistern, and prepontine cistern. Volumes were also calculated for intraparenchymal hemorrhages and hemorrhages within the left and right lateral, third, and fourth ventricles. Interestingly, in their patient population, few had either intraparenchymal hemorrhages or IVHs, and thus both were recorded as either present or 
absent. As expected, the authors found a strong linear correlation between the volume of cisternal blood and the development of DINDs. All 13 patients with total cisternal or total overall hemorrhage volumes greater than 20 $\mathrm{ml}$ suffered moderate or severe DINDs. With cisternal hemorrhage volumes less than $20 \mathrm{ml}, 15$ of 27 patients still experienced DINDs. Therefore, the value $20 \mathrm{ml}$ carries a $100 \%$ specificity and PPV, but a low sensitivity and NPV (Table 1). The presence of IVH or ICH was not associated with DINDs, although this was probably because of the low frequency of occurrence in the study population.

In the most recent contributions to the development of a model, researchers have investigated the clearance of blood as a possible predictor of vasospasm. It would stand to reason that blood that is not mobilized and washed away early after the ictal event would predispose the patient to development of vasospasm. Researchers have tried to enhance clot clearance actively with mechanical options, ${ }^{34}$ cisternal drainage,${ }^{33}$ and intracisternal administration of fibrinolytic agents, ${ }^{14}$ and passively with the use of a lumbar drain. ${ }^{38}$ Several Japanese researchers found that vasospasm did not develop in cases in which the HN values fell rapidly in 4 to 5 days. ${ }^{40,68}$ Also, those patients in whom vasospasm did develop did not have a reduction of their $\mathrm{HN}$ values to less than 60 even several days later. Fisher, et al., ${ }^{15}$ observed rather quick reversal of vasospasm in three of their patients. They speculated that this occurred because of prompt restoration of a relatively unobstructed flow of CSF that carried away the spasmogenic agent, and that "delayed reversal would represent the opposite-persistence of a subarachnoid clot, continued activity of the [spasmogenic] agent, and lingering vasospasm."

One of the first papers in which researchers looked specifically at the clearance of cisternal SAH was written by Brouwers, et al. ${ }^{7}$ Cerebral infarction, used as a surrogate indicator of vasospasm, was found to be related to the total amount but not to the distribution or clearance rate of extravasated subarachnoid blood. These findings were contradicted by Hirashima and colleagues ${ }^{27}$ in their 1995 paper. They studied 69 patients and graded their CT scans according to the method described by Hijdra, et al. Of their patients, 24 (35\%) suffered infarctions. The total score of subarachnoid blood on admission and postoperatively was higher and the clearance rate was lower in patients with cerebral infarction than in those without, and the predominant site of subarachnoid blood corresponded with the site of the infarct. The presence of an intracerebral hematoma and ventricular blood were not related to the development of vasospasm-induced infarction. Most recently, Reilly, et al., ${ }^{60}$ found that the initial clot volume and percentage of clot cleared per day were significant predictors of vasospasm in their cohort of 75 patients, whereas the Fisher grade and initial clot density were not.

\section{Conclusions}

Since the first description of aneurysmal SAH on CT scans in the late 1970s, the amount of blood has been positively correlated with the risk of developing symptomatic vasospasm and vasospasm-induced cerebral infarction. Many scales have been proposed to grade the amount of cisternal subarachnoid blood in the hopes of more accu- rately determining which patients are at highest risk. The most well-known scale that continues to be used is the one created by Fisher, et al.; however, other more elaborate and comprehensive scales, such as the one proposed by Hijdra, et al., have been published. The majority of current evidence seems to support the suggestion that the presence of significant IVH is also a risk factor for vasospasm; intracerebral hematomas, on the other hand, have consistently been shown not to be a risk factor.

Most recently, commercially available software packages have enabled a more accurate quantification of hemorrhage volume and clearance rate, and these factors have been shown to be predictors of vasospasm. Clearly, the risk of vasospasm can be more accurately stratified using other classification schemes than the widely used Fisher scale. In studies of interventions to prevent vasospasm, it is critical that an appropriate risk stratification scheme be used to balance the assignment of patients between treatment and control groups to prevent bias. The findings on CT scans are but one of many known and unknown factors that contribute to the individual's risk that vasospasm and its sequela, infarction, will develop. Future research should be directed to the creation of multifactorial predictive models that incorporate not only CT data, but also other modifiable and nonmodifiable clinical factors in the hopes of determining with the greatest accuracy which patients will suffer vasospasm. This would save low-risk patients from unnecessary procedures and risks and allow initiation of early, aggressive treatment for high-risk patients.

\section{Note Added in Proof}

Frontera, et al., using the same tirilazad study database as Macdonald, et al., compared the original Fisher scale to a modified one in terms of predicting vasospasm. Their work was published in the July 2006 issue of Neurosurgery (Frontera JA, Claassen J, Schmidt JM, Wartenberg KE, Temes R, Connolly ES Jr., et al: Prediction of symptomatic vasospasm after subarachnoid hemorrhage: the modified fisher [sic] scale. Neurosurgery 59:21-27; discussion 21-27, 2006). Their modified scale criteria were as follows: Grade 0, no SAH or IVH; Grade 1, focal or diffuse thin SAH with no IVH; Grade 2, focal or diffuse thin SAH with IVH; Grade 3, focal or diffuse thick SAH with no IVH; and Grade 4, focal or diffuse thick SAH with IVH. This modification of the Fisher scale showed a stronger association of $\mathrm{CT}$ findings with symptomatic vasospasm than the original scale. When their modified scale was placed in a multivariate model along with other factors found to be predictors on univariate analysis (early angiographic vasospasm, mean arterial pressure $\geq 112$ $\mathrm{mm} \mathrm{Hg}$, history of hypertension, and poor neurological grade), it remained a significant and independent predictor of symptomatic vasospasm, whereas the original Fisher scale did not. The paper by Frontera, et al., thus provides additional evidence that IVH, in combination with $\mathrm{SAH}$, contributes significantly to the risk of developing vasospasm.

\section{References}

1. Adams HP Jr, Kassell NF, Torner JC, Haley EC Jr: Predicting cerebral ischemia after aneurysmal subarachnoid hemorrhage: 
influences of clinical condition, CT results, and antifibrinolytic therapy: a report of the Cooperative Aneurysm Study. Neurology 1987:1586-1591, 1987

2. Allen GS, Ahn HS, Preziosi TJ, Battye R, Boone SC, Boone $\mathrm{SC}$, et al: Cerebral arterial spasm - a controlled trial of nimodipine in patients with subarachnoid hemorrhage. N Engl J Med 308:619-624, 1983

3. Bell BA, Kendall BE, Symon L: Computed tomography in aneurysmal subarachnoid haemorrhage. J Neurol Neurosurg Psychiatry 43:522-524, 1980

4. Borsody M, Burke A, Coplin W, Miller-Lotan R, Levy A: Haptoglobin and the development of cerebral artery vasospasm after subarachnoid hemorrhage. Neurology 66:634-640, 2006

5. Broderick JP, Brott TG, Duldner JE, Tomsick T, Leach A: Initial and recurrent bleeding are the major causes of death following subarachnoid hemorrhage. Stroke 25:1342-1347, 1994

6. Brouwers PJ, Dippel DW, Vermeulen M, Lindsay KW, Hasan D, van Gijn J: Amount of blood on computed tomography as an independent predictor after aneurysm rupture. Stroke 24: 809-814, 1993

7. Brouwers PJ, Wijdicks EF, van Gijn J: Infarction after aneurysm rupture does not depend on distribution or clearance rate of blood. Stroke 23:374-379, 1992

8. Charpentier C, Audibert G, Guillemin F, Civit T, Ducrocq X, Bracard S, et al: Multivariate analysis of predictors of cerebral vasospasm occurrence after aneurysmal subarachnoid hemorrhage. Stroke 30:1402-1408, 1999

9. Claassen J, Bernardini GL, Kreiter K, Bates J, Du YE, Copeland D, et al: Effect of cisternal and ventricular blood on risk of delayed cerebral ischemia after subarachnoid hemorrhage. The Fisher Scale revisited. Stroke 32:2012-2020, 2001

10. Conway JE, Tamargo RJ: Cocaine use is an independent risk factor for cerebral vasospasm after aneurysmal subarachnoid hemorrhage. Stroke 32:2338-2343, 2001

11. Davis JM, Davis KR, Crowell RM: Subarachnoid hemorrhage secondary to ruptured intracranial aneurysm: prognostic significance of cranial CT. AJR Am J Roentgenol 34:711-715, 1980

12. Dehdashti AR, Mermillod B, Rufenacht DA, Reverdin A, de Tribolet N: Does treatment modality of intracranial ruptured aneurysms influence the incidence of cerebral vasospasm and clinical outcome? Cerebrovasc Dis 17:53-60, 2004

13. Findlay JM, Deagle GM: Causes of morbidity and mortality following intracranial aneurysm rupture. Can J Neurol Sci 25:209-215, 1998

14. Findlay JM, Kassell NF, Weir BKA, Haley EC Jr, Kongable G, Germanson $\mathrm{T}$, et al: A randomized trial of intraoperative, intracisternal tissue plasminogen activator for the prevention of vasospasm. Neurosurgery 37:168-178, 1995

15. Fisher CM, Kistler JP, Davis JM: Relation of cerebral vasospasm to subarachnoid hemorrhage visualized by CT scanning. Neurosurgery 6:1-9, 1980

16. Fisher CM, Robertson GH, Ojemann RG: Cerebral vasospasm with ruptured saccular aneurysm-the clinical manifestations. Neurosurgery 1:245-248, 1977

17. Fraser J, Johnson S, Ray M, Robertson JT: Prediction of cerebral vasospasm with subarachnoid hemorrhage due to ruptured intracranial aneurysm by computed axial tomography. Neurosurgery 6:686-687, 1980 (Abstract)

18. Friedman JA, Goerss SJ, Meyer FB, Piepgras DG, Pichelmann MA, McIver JI, et al: Volumetric quantification of Fisher Grade 3 aneurysmal subarachnoid hemorrhage: a novel method to predict symptomatic vasospasm on admission computerized tomography scans. J Neurosurg 97:401-407, 2002

19. Fujita S: Computed tomographic grading with Hounsfield number related to delayed vasospasm in cases of ruptured cerebral aneurysm. Neurosurgery 17:609-612, 1985

20. Gilsbach JM, Harders AG, Eggert HR, Hornyak ME: Early aneurysm surgery: a 7 year clinical practice report. Acta Neurochir (Wein) 90:91-102, 1988
21. Grosset DG, McDonald I, Cockburn M, Straiton J, Bullock RR: Prediction of delayed neurological deficit after subarachnoid haemorrhage: a CT blood load and Doppler velocity approach. Neuroradiology 36:418-421, 1994

22. Gurusinghe NT, Richardson AE: The value of computerized tomography in aneurysmal subarachnoid hemorrhage. The concept of the CT score. J Neurosurg 60:763-770, 1984

23. Harrod CG, Bendok BR, Batjer HH: Prediction of cerebral vasospasm in patients presenting with aneurysmal subarachnoid hemorrhage: a review. Neurosurgery 56:633-654, 2005

24. Hijdra A, Brouwers PJ, Vermeulen M, van Gijn J: Grading the amount of blood on computed tomograms after subarachnoid hemorrhage. Stroke 21:1156-1161, 1990

25. Hijdra A, van Gijn J, Nagelkerke NJ, Vermeulen M, van Crevel $\mathrm{H}$ : Prediction of delayed cerebral ischemia, rebleeding, and outcome after aneurysmal subarachnoid hemorrhage. Stroke 19: $1250-1256,1988$

26. Hirashima $Y$, Hamada H, Kurimoto M, Origasa H, Endo S: Decrease in platelet count as an independent risk factor for symptomatic vasospasm following aneurysmal subarachnoid hemorrhage. J Neurosurg 102:882-887, 2005

27. Hirashima Y, Kurimoto M, Takaba M, Endo S, Takaku A: The use of computed tomography in the prediction of delayed cerebral infarction following acute aneurysm surgery for subarachnoid haemorrhage. Acta Neurochir (Wien) 132:9-13, 1995

28. Hirashima Y, Kurimoto M, Tsukamoto E, Endo S, Takaku A: Anti-phospholipid antibodies and cerebral vasospasm following subarachnoid haemorrhage. Acta Neurochir (Wien) 135: 191-197, 1995

29. Hoh BL, Topcuoglu MA, Singhal AB, Pryor JC, Rabinov JD, Rordorf GA, et al: Effect of clipping, craniotomy, or intravascular coiling on cerebral vasospasm and patient outcome after aneurysmal subarachnoid hemorrhage. Neurosurgery 55: 779-789, 2004

30. Kamezaki T, Yanaka K, Nagase S, Fujita K, Kato N, Nose T: Increased levels of lipid peroxides as predictive of symptomatic vasospasm and poor outcome after aneurysmal subarachnoid hemorrhage. J Neurosurg 97:1302-1305, 2002

31. Kassell NF, Sasaki T, Colohan AR, Nazar G: Cerebral vasospasm following aneurysmal subarachnoid hemorrhage. Stroke 16:562-572, 1985

32. Kassell NF, Torner JC, Haley EC Jr, Jane JA, Adams HP, Kongable GL: The International Cooperative Study on the Timing of Aneurysm Surgery. Part 1. Overall management result. J Neurosurg 73:18-36, 1990

33. Kawakami Y, Shimamura Y: Cisternal drainage after early operation of ruptured intracranial aneurysm. Neurosurgery 20: 8-14, 1987

34. Kawamoto S, Tsutsumi K, Yoshikawa G, Shinozaki MH, Yako $K$, Nagata K, et al: Effectiveness of the head-shaking method combined with cisternal irrigation with urokinase in preventing cerebral vasospasm after subarachnoid hemorrhage. J Neurosurg 100:236-243, 2004

35. Kawano T, Yonekawa Y: Serum complements as indicator for predicting vasospasm and its severity after aneurysmal subarachnoid hemorrhage. Nippon Geka Hokan 59:189-197, 1990

36. Khurana VG, Sohni YR, Mangrum WI, McClelland RL, O'Kane DJ, Meyer FB, et al: Endothelial nitric oxide synthase gene polymorphisms predict susceptibility to aneurysmal subarachnoid hemorrhage and cerebral vasospasm. J Cereb Blood Flow Metab 24:291-297, 2004

37. Kistler JP, Crowell RM, Davis KR, Heros R, Ojemann RG, Zervas T, et al: The relation of cerebral vasospasm to the extent and location of subarachnoid blood visualized by CT scan: a prospective study. Neurology 33:424-436, 1983

38. Klimo P Jr, Kestle JRW, MacDonald JD, Schmidt RH: Marked reduction of cerebral vasospasm with lumbar drainage of cerebrospinal fluid after subarachnoid hemorrhage. J Neurosurg 100:215-224, 2004 
39. Knuckey NW, Fox RA, Surveyor I, Stokes BAR: Early cerebral blood flow and computerized tomography in predicting ischemia after cerebral aneurysm rupture. J Neurosurg 62: $850-855,1985$

40. Komatsu S, Sato T, Ogawa A, Sakurai Y, Suzuki J: [Correlation between $\mathrm{CT}$ findings and subsequent development of cerebral infarction due to vasospasm in subarachnoid hemorrhage cases.] Neurol Med Chir (Tokyo) 21:373-377, 1981 (Jpn)

41. Kothari RU, Brott T, Broderick JP, Barsan WG, Sauerbeck LR, Zuccarello M, et al: The ABCs of measuring intracerebral hemorrhage volumes. Stroke 27:1304-1305, 1996

42. Lanzino G, Kassell NF, Germanson T, Truskowski L, Alves W: Plasma glucose levels and outcome after aneurysmal subarachnoid hemorrhage. J Neurosurg 79:885-891, 1993

43. Lanzino G, Kassell NF, Germanson TP, Kongable GL, Truskowski LL, Torner JC, et al: Age and outcome after aneurysmal subarachnoid hemorrhage: why do older patients fare worse? J Neurosurg 85:410-418, 1996

44. Lasner TM, Weil RJ, Riina HA, King JT Jr, Zager EL, Raps EC, et al: Cigarette smoking-induced increase in the risk of symptomatic vasospasm after aneurysmal subarachnoid hemorrhage. J Neurosurg 87:381-384, 1997

45. Lindsay KW, Teasdale GM, Knill-Jones RP, Murray L: Observer variability in grading patients with subarachnoid hemorrhage. J Neurosurg 56:628-633, 1982

46. Macdonald RL, Rosengart A, Huo D, Karrison T: Factors associated with the development of vasospasm after planned surgical treatment of aneurysmal subarachnoid hemorrhage. J Neurosurg 99:644-652, 2003

47. Mascia L, Fedorko L, terBrugge K, Filippini C, Pizzio M, Ranieri VM, et al: The accuracy of transcranial Doppler to detect vasospasm in patients with aneurysmal subarachnoid hemorrhage. Intensive Care Med 29:1088-1094, 2003

48. McGirt MJ, Lynch JR, Blessing R, Warner DS, Friedman AH, Laskowitz DT: Serum von Willebrand factor, matrix metalloproteinase-9, and vascular endothelial growth factor levels predict the onset of cerebral vasospasm after aneurysmal subarachnoid hemorrhage. Neurosurgery 51:1128-1135, 2002

49. McGirt MJ, Mavropoulos JC, McGirt LY, Alexander MJ, Friedman AH, Laskowitz DT, et al: Leukocytosis as an independent risk factor for cerebral vasospasm following aneurysmal subarachnoid hemorrhage. J Neurosurg 98:1222-1226, 2003

50. Mizukami M, Takemae T, Tazawa T, Kawase T, Matsuzaki T: Value of computed tomography in the prediction of cerebral vasospasm after aneurysm rupture. Neurosurgery 7:583-586, 1980

51. Mocco J, Ransom ER, Komotar RJ, Mack WJ, Sergot PB, Albert SM, et al: Racial differences in cerebral vasospasm: a systematic review of the literature. Neurosurgery 58:305-314, 2006

52. Mohsen F, Pomonis S, Illingworth R: Prediction of delayed cerebral ischemia after subarachnoid haemorrhage by computed tomography. J Neurol Neurosurg Psychiatry 47: 1197-1202, 1984

53. Newell DW, Winn HR: Transcranial Doppler in cerebral vasospasm. Neurosurg Clin N Am 1:319-328, 1990

54. Pasqualin A, Rosta L, Da Pian R, Cavazzani P, Scienza R: Role of computed tomography in the management of vasospasm after subarachnoid hemorrhage. Neurosurgery 15:344-353, 1984

55. Pickard JD, Murray GD, Illingworth R, Shaw MD, Teasdale GM, Foy PM, et al: Effect of oral nimodipine on cerebral infarction and outcome after subarachnoid haemorrhage: British aneurysm nimodipine trial. Br Med J 298:636-642, 1989

56. Qureshi AI, Suarez JI, Bhardwaj A, Yahia AM, Tamargo RJ, Ulatowski JA: Early predictors of outcome in patients receiving hypervolemic and hypertensive therapy for symptomatic vasospasm after subarachnoid hemorrhage. Crit Care Med 28: 824-829, 2000
57. Qureshi AI, Sung GY, Razumovsky AY, Lane K, Straw RN, Ulatowski JA: Early identification of patients at risk for symptomatic vasospasm after aneurysmal subarachnoid hemorrhage. Crit Care Med 28:984-990, 2000

58. Rabb CH, Tang G, Chin LS, Giannotta SL: A statistical analysis of factors related to symptomatic cerebral vasospasm. Acta Neurochir (Wien) 127:27-31, 1994

59. Rabinstein AA, Friedman JA, Weigand SD, McClelland RL, Fulgham JR, Manno EM, et al: Predictors of cerebral infarction in aneurysmal subarachnoid hemorrhage. Stroke 35: 1862-1866, 2004

60. Reilly C, Amidei C, Tolentino J, Jahromi BS, Macdonald RL: Clot volume and clearance rate as independent predictors of vasospasm after aneurysmal subarachnoid hemorrhage. J Neurosurg 101:255-261, 2004

61. Roos YBWEM, de Haan RJ, Beene LFM, Groen RJM, Albrecht KW, Vermeulen M: Complications and outcome in patients with aneurysmal subarachnoid haemorrhage: a prospective hospital based cohort study in The Netherlands. J Neurol Neurosurg Psychiatry 68:337-341, 2000

62. Sano H, Kanno T, Shinomiya Y, Katada K, Katoh Y, Nakagawa T, et al: Prospection of chronic vasospasm by CT findings. Acta Neurochir (Wien) 63:23-30, 1982

63. Schaller C, Rohde V, Meyer B, Hassler W: Amount of subarachnoid blood and vasospasm: current aspects. A transcranial Doppler study. Acta Neurochir (Wien) 136:67-71, 1995

64. Seiler R, Binggeli R: Is cerebral vasospasm still a clinical problem? Acta Neurochir Suppl 77:1-4, 2001

65. Seiler RW, Reulen HJ, Huber P, Grolimund P, Ebeling U, Steiger HJ: Outcome of aneurysmal subarachnoid hemorrhage in a hospital population: a prospective study including early operation, intravenous nimodipine, and transcranial Doppler ultrasound. Neurosurgery 23:598-604, 1988

66. Smith ML, Abrahams JM, Chandela S, Smith MJ, Hurst RW, Le Roux PD: Subarachnoid hemorrhage on computed tomography scanning and the development of cerebral vasospasm: the Fisher grade revisited. Surg Neurol 63:229-234, 2005

67. Solenski NJ, Haley EC Jr, Kassell NF, Kongable G, Germanson $\mathrm{T}$, Truskowski L, et al: Medical complications of aneurysmal subarachnoid hemorrhage: a report of the multicenter, cooperative aneurysm study. Crit Care Med 23:1007-1017, 1995

68. Suzuki J, Komatsu S, Sato T, Sakurai Y: Correlation between CT findings and subsequent development of cerebral infarction due to vasospasm in subarachnoid haemorrhage. Acta Neurochir (Wien) 55:63-70, 1980

69. Sviri GE, Feinsod M, Soustiel JF: Brain natriuretic peptide and cerebral vasospasm in subarachnoid hemorrhage: clinical and TCD correlations. Stroke 31:118-122, 2000

70. Takemae T, Mizukami M, Kin H, Kawase T, Araki G: [Computed tomography of ruptured intracranial aneurysms in acute stage - relationship between vasospasm and high density on CT scan.] No To Shinkei 30:861-866, 1978 (Jpn)

71. van der Jagt $M$, Hasan D, Bijvoet HWC, Pieterman H, Koudstaal PJ, Avezaat CJJ: Interobserver variability of cisternal blood on CT after aneurysmal subarachnoid hemorrhage. Neurology 54:2156-2158, 2000

72. Weir BKA, Kongable GL, Kassell NF, Schultz JR, Truskowski LL, Sigrest A: Cigarette smoking as a cause of aneurysmal subarachnoid hemorrhage and risk for vasospasm: a report of the Cooperative Aneurysm Study. J Neurosurg 89:405-411, 1998

Manuscript received June 16, 2006.

Accepted in final form August 4, 2006.

Address reprint requests to: Richard H. Schmidt, M.D., Ph.D., Department of Neurosurgery, University of Utah, 3B-409 SOM, 30 North 1900 East, Salt Lake City, Utah 84132-2303. email: rhs@ suzy.med.utah.edu. 